\title{
Ideologías lingüísticas del español en comunidades y páginas de Facebook: políticas de lengua e identidad social en Chile contemporáneo
}

\section{Language ideologies on Spanish in Facebook pages and communities: language and social identity policies in contemporary Chile}

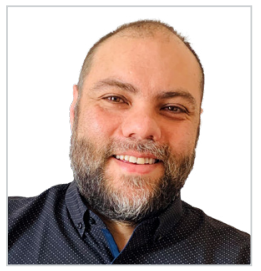

Gabriel Eduardo Alvarado Pavez. Doctor en Culturas Latinas, Latinoamericanas e Ibéricas de City University de New York-CUNY- (2020) y Magíster en Lingüística Hispánica, Universidad de Chile (2011), tiene una maestría en Lexicografía de ASALE, Madrid (2006). Lingüista, lexicógrafo, traductor y educador. Se ha dedicado a la docencia del español y de lingüística hispánica en Chile, Egipto (2004), y Estados Unidos (2014-2020). Entre 2006-2014 ha colaborado en la producción de diccionarios de la lengua española con la Academia Chilena de la Lengua. Su tesis de doctorado se titula "Glotopolítica de la desigualdad: Ideologías del mapudungun y el español en Chile". Hoy se dedica a la investigación de ideologías lingüísticas en medios contemporáneos, y a estudiar chino mandarín y latín clásico.

Universidad de la Ciudad de Nueva York, Estados Unidos

galvaradopavez@gradcenter.cuny.edu

ORCID: 0000-0002-5305-2352

Recibido: 01/07/2020 - Aceptado: 20/10/2020

Resumen:

En el presente artículo se abordan los discursos acerca del español y su desenvolvimiento en el contexto de Chile en el siglo XXI mediante la observación de discursos sobre la lengua en Facebook entre los años 2009 y 2019. El estudio consistió en un rastreo de grupos y páginas con administración chilena donde se discuten políticas de lengua e identidad en el contexto chileno. Resultó en la detección de diversos fenómenos particulares, entre ellos, la minimización de los problemas de lengua como relevantes en el país; la escasa presencia de tropos ideológicos de orgullo nacional; y, notablemente, la emergencia de una renovación del ideologema en torno a que en Chile "se habla mal" a partir de urgencias de orden político e identitario. Hubo también casos en los que se detectó una revaloración del español chileno, en especial de las clases populares. Todo ello contrasta con una visión fuertemente positiva de la lengua mapuche o mapudungun, la lengua originaria más hablada del país, y una expansión de su alcance político.

Palabras clave:

Español de Chile; Glotopolítica del español en redes sociales; Ideologías de lengua en internet; Corpus lingüístico de redes sociales; Sociolingüística crítica en redes sociales.
Received: 01/07/2020 - Accepted: 20/10/2020

\section{Abstract:}

This paper addresses discourses about Spanish and its development in the Chilean context in the 21st century by analyzing exchanges about language on Facebook between 2009 and 2019. The study focused on Facebook communities and pages administered from Chile, in which language and identity policies are discussed in the Chilean context. Research led to the detection of phenomena such the minimization of language problems as relevant within Chile's digital space; a scarce presence of ideological tropes of national pride; and, notably, the emergence of a renewal of the ideology around the fact that in Chile "people speak poorly" based on political and identity necessities. There were also detections of a revaluation of Chilean Spanish, especially among the lower classes. All this contrasts with a positive vision of the Mapuche or Mapudungun language, the most widely spoken native language in the country, and an expansion of its political reach.

\section{Keywords:}

Chilean Spanish; Spanish language Glottopolitics in Social Media; Language Ideologies Online; Social Media as Linguistic Corpora; Social Media Critical Sociolinguistics.

\footnotetext{
Cómo citar este artículo:

Alvarado Pavez, G. E. (2020). Ideologías lingüísticas del español en comunidades y páginas de Facebook: políticas de lengua e identidad social en Chile contemporáneo. Doxa Comunicación, 31, pp. 265-281. https://doi.org/10.31921/doxacom.n31a13
} 


\section{Introducción}

El modo en que se configura ideológicamente el español en Chile en el contexto contemporáneo posee una serie de singularidades difícilmente caracterizables de manera concisa. A grandes rasgos, ello calza con cómo se observa el objeto lengua en un momento disciplinar en el que los atributos asignados a dicho objeto desde la lingüística (inmovilidad, sincronía, organización interna, distribución diatópica) entran, hasta cierto punto, en crisis. Existe una visión disciplinaria que pone cada vez más atención a la movilidad, discontinuidad temporal, inestabilidad sistémica, deslocalización y multipolaridad de la producción de los discursos. En directa relación con esta concepción de los objetos de análisis sociolingüístico como complejos, como sugiere Blommaert (2014), las redes sociales como Facebook constituyen registros de gran calidad de cómo las representaciones socialmente relevantes emergen, circulan, se debaten y se negocian, lo cual ocurre en buena medida porque Internet conforma espacios donde por excelencia hoy se gestionan y configuran transformaciones en el ámbito político, ideológico y social (Phyak, 2015; Deumert, 2015, Blommaert et al., 2009).

En el presente trabajo observaremos cómo se piensan y desafían nociones de lengua y diversidad, trayendo a la luz los modos complejos en que estas se articulan en espacios de la red social Facebook articulados para y por hablantes de español en Chile. El objetivo principal es dar cuenta de la presencia (o ausencia) de ciertas ideologías de lengua en el corpus, y de sus características, de modo de acotar brevemente su proyección en el contexto histórico político de Chile contemporáneo.

La noción de ideología lingüística adscrita aquí remite a "marcos cognitivos que ligan coherentemente el lenguaje con un orden extralingüístico, naturalizándolo, y normalizándolo” (Del Valle y Meirinho, 2016). Es decir, estos marcos no sólo refieren a la lengua, sino que se atribuyen órdenes sociales y culturales específicos (por ejemplo, los que remiten a identidad, comunidad, nación, Estado, género) profundamente imbricados con estructuras de poder, en cuya constitución y permanencia cooperan activamente. Arnoux y Del Valle (2010) proponen que las ideologías lingüísticas se sostienen en ideologemas, "lugares comunes, postulados o máximas" que funcionan como presupuestos del discurso, como por ejemplo, "En Chile se habla mal (español)".

Woolard (2007) sugiere la prevalencia de algunas ideologías lingüísticas que representan nociones epistemológicas y morales de raigambre occidental en el mundo global contemporáneo, como por ejemplo, el anonimato, que entiende una determinada lengua como una voz pública, despersonalizada y deslocalizada y es frecuente en casos de lenguas hegemónicas transnacionales. El inglés, por ejemplo, se posiciona como la lengua anónima por defecto no solo en los estados nacionales donde predomina, sino que también en ámbitos digitales a nivel global (Ricento 2015). Del Valle (2007) da evidencias de discursos hegemónicos contemporáneos en torno al español como lengua posnacional, común, mestiza, y con acceso privilegiado a la modernidad. Esta visión es común entre agentes de gestión y planificación lingüística centrada en la institucionalidad de la Academias de la Lengua Española, pero también en la industria editorial y la enseñanza de español como lengua extranjera (Del Valle, 2014). Woolard (2007) sugiere que reconocer una lengua como "anónima" requiere de la aceptación popular de la autoridad de dicho anonimato, un proceso llamado méconnaissance por Bourdieu (1991), el cual ocurre principalmente en la escuela. En este proceso se purga a la variedad de lengua dominante de su origen social específico, imaginándola como un atributo natural de la autoridad, transparente y garantizado en la 
comunicación social. Desde una perspectiva crítica, ello oculta el hecho fundamental de que, inevitablemente, la lengua anónima siempre ha de pertenecer más unos que a otros, en tanto las clases dominantes típicamente detentan control y acceso a dicha lengua.

Otra ideología lingüística de interés aquí y discutida por la teoría es la representación de la lengua como algo que confirma la autenticidad cultural de quien la habla (Woolard 2007). Esto es frecuente, por ejemplo en el caso del catalán en la comunidad autónoma de Cataluña (Woolard, 2016), pero también en el español entre hispanohablantes en Nueva York (García y Otheguy, 2014), o el mapudungun en Chile (Gundermann, 2014). Con frecuencia se asocia a proyectos reivindicativos de grupos identitarios minoritarios o al ensalzamiento de lo nacional. Asimismo, la autenticidad se empalma $o$ complementa con discursos de orgullo (Heller y Duchêne, 2012), en los que se exacerba aquello considerado propio o exclusivo de un determinado grupo humano, el cual puede conllevar a una esencialización de sus límites y de sus supuestos atributos intrínsecos, algo observable con frecuencia en discursos de afirmación identitaria.

Para el caso de Chile, además, emerge con frecuencia la ideología lingüística de que el español chileno es incorrecto o implica hablar mal, un tropo reproducido con frecuencia no solo dentro del país sino que a escala transnacional, con diversas aristas (Sliashynskaya, 2019; Rojas, 2015). Puntualmente, creemos que esta ideología varía según escalas: mientras que en ámbitos transnacionales empuja a la reproducción de asimetrías simbólicas donde determinadas variedades de lengua son consideradas superiores (“centrales" o "estándar"), en la escala nacional se vincula íntimamente a modos locales de reproducir inequidades de clase social en el sistema educativo y cultural. En este sentido esta visión empalma con la ideología de la lengua estándar, que presupone una jerarquía de variedades lingüísticas donde la más deseable es aquella que se apega más a una forma supuestamente neutra (Milroy, 2001). En escalas aún menores, creemos, el ideologema en Chile se habla mal obedece menos a reglas fijas y más a microdinámicas de poder actualizadas en una práctica constante de higiene verbal (Cameron, 2012), es decir, de un control directo sobre qué es admisible en la práctica lingüística. En este caso, dicho control está ligado a la perpetuación, mediante la interacción interpersonal, de un sistema de inequidades simbólicas y materiales firmemente arraigadas en una sociedad extraordinariamente desigual.

En el presente artículo se discute cómo estas y otras ideologías en torno a la lengua en Chile circulan en Facebook, en tanto este espacio digital presenta características idóneas para documentar su negociación. Dadas las configuraciones textuales propias del entorno digital, las ideologías de lengua en Facebook informan acerca de visiones sobre la sociedad y la identidad chilenas de fuerte raigambre histórica, y que, no obstante, persisten en modos actuales de dominación sociocultural que, tal vez como nunca antes, están en rápido proceso de transformación.

\section{Metodología}

La metodología ocupada aquí se halla enraizada en el análisis textual de ideologías lingüísticas desde una perspectiva sociolingüística crítica, glotopolítica, es decir, que entiende el lenguaje como hecho político, necesariamente involucrado en la constitución del poder, en todas sus escalas e irradiaciones. En este sentido, la mirada glotopolítica se dirige hacia acciones lingüísticas no solo por parte de aparatos institucionales, sino también en los diversos discursos que constituyen subjetividad e identidad (Del Valle, 2017; Arnoux y Del Valle, 2010). En concordancia con esta visión, el presente análisis es 
de carácter cualitativo, y se enfoca en la caracterización de las configuraciones de los discursos sociales en escalas específicas y través de diversos puntos de entrada. Se vale de ideología lingüística a la vez como objeto e instrumento de estudio, de manera que torna operativas las dimensiones complejas en las que se constituyen los discursos contemporáneos, no solo como objetos separables de la producción de conocimiento, sino como unidades productivas en sí mismas (Gal y Woolard, 2001b). En este sentido, es acertado acoplarnos a un paradigma de complejidad del análisis sociolingüístico (Blommaert, 2014), que entiende a su objeto como permanentemente mutable, ilimitado, policéntrico, multidireccional e impredecible. En concordancia con esta visión, el presente trabajo no apunta a reducir la complejidad o concentrarla en modelos estáticos, sino demostrarla y hacerla visible.

El carácter cualitativo del presente análisis, no obstante, no minimiza el valor de las ausencias y vacíos en el corpus. Es más, también posee una dimensión cuantitativa de momento en que señala el valor cero de determinados fenómenos de lengua, y como se observará más adelante, la ausencia o presencia de determinadas representaciones resultará grandemente informativo del modo en que se configura el español en el contexto chileno, en particular si se lo pone en perspectiva junto con otros ámbitos o escalas de la lengua española o de otras lenguas transnacionales.

Durante la etapa de exploración inicial que condujo al presente trabajo se recolectaron documentos de corpus proveniente de grupos y páginas de Facebook de tres momentos dados inmediatamente antes, durante y después de las elecciones presidenciales de Chile de los años 2009-2010, 2013 y 2017. Estos cierres temporales permiten dar testimonio de la paulatina emergencia de las redes sociales y de su impacto general, y, por otro, al incremento del peso político de grupos históricamente marginados, especialmente a través de las multimodalidades digitales, en períodos de alta discusión y debate político nacional.

Se eligió Facebook como fuente de datos en lugar de otros espacios virtuales de comunicación interpersonal digital (WhatsApp, Twitter, Instagram, u otros) principalmente porque en la década de 2010 se perfiló claramente como la red social de mayor penetración en el mundo. El semanario británico The Economist en un artículo del 20 de julio de 2019 indica que hacia mediados de 2018 Facebook superaba con holgura los 2.000 millones de usuarios y que, a diferencia de momentos anteriores, una proporción importante de ellos corresponde a personas de edad adulta o avanzada. Esto es coherente con un momento en que la influencia de Facebook es claramente determinante de procesos políticos tanto a escala global como local. En la década de 2010, protestas y movimientos sociales de todo el planeta y de los más variados signos políticos han utilizado Facebook como plataforma clave de articulación y movilización: tanto Alt-Right como Black Lives Matter, en Estados Unidos; las protestas que gatillaron la llamada Primavera Árabe en Oriente Medio y la Revolución de los Paraguas en Hong Kong; o los movimientos Me Too y Ni una menos. Del mismo modo, en Chile, Facebook ha sido y es utilizado por los más diversos sectores de la sociedad nacional, y su impacto en los modos de asociación y producción cultural es inmenso. Para los propósitos de esta indagación la característica más favorable de Facebook es su capacidad de conducir a la constitución de grupos de interés específicamente centrados en iniciativas comunitarias, así como en una gestión de sus propios proyectos sociales y políticos (Phyak, 2015; Blommaert et al., 2009). Esto permite recolectar evidencia con respecto a qué intereses concurren en un determinado ámbito social. Así quienes participan en las comunidades se involucran constantemente en debates en torno a lo político y lo identitario, desplegando con detalle ideologías lin- 
güísticas implícitas y explícitas, así como sus correlatos extralingüísticos. Convenientemente, en Facebook la producción de contenidos es susceptible de ser fechada y localizada, y sus productores son (hasta cierto punto) rastreables.

En el momento de la recolección del corpus de trabajo nos enfocamos en dos modalidades de interfaz de Facebook: las comunidades y las páginas. Estas últimas son portales fácilmente accesibles que proporcionan información abierta y gratuita acerca de empresas, instituciones o agrupaciones con diversos grados de formalidad. En cambio, las comunidades (hasta 2018 llamadas grupos) están dirigidas principalmente a la interacción y al contacto entre sus miembros y pueden ser de acceso público -es decir, de libre adhesión para cualquiera que tenga un perfil en Facebook-, o restringido, es decir, que requieren del permiso de un administrador.

El análisis de comunidades y páginas partió con una etapa inicial denominada de rastreo, que consistía en un procedimiento general de detección de comunidades y páginas correspondientes a grupos interesados en problemas de lengua e identidad en Chile, facilitado por el uso de herramientas de navegación internas de Facebook. Tuvo lugar en cuatro momentos de rastreo: agosto 2018, julio 2019, noviembre 2019 y mayo 2020. Supuso valerse del sistema de búsqueda que permite utilizar palabras clave con filtros temporales en la interfaz de navegadores como Mozilla Firefox y Google Chrome. Como se ha descrito anteriormente, los filtros temporales se corresponden con las fechas del mes de cada una de elecciones presidenciales de los años 2009, 2013 y 2017, más el mes anterior y el posterior. Se eligió estos meses porque se supuso una mayor cantidad de debate político lingüístico en estas fechas. No obstante, dada la naturaleza reticular de los contenidos de Facebook y los sistemas de referencia hipertextual que ligan documentos digitales (artículos de prensa digital; textos breves y comentarios; imágenes, tales como memes, gráficos, vídeos, etc.) fue preciso contemplar la temporalidad de dicha producción hipertextual de manera móvil, en tanto no es posible establecer límites de una sincronía formal en el sentido tradicional. Esto obedece a que si un documento digital (por ejemplo, una imagen más sus comentarios) es posteado en una cierta fecha, este puede repostearse o tornarse accesible nuevamente en fechas posteriores, bien gracias a la voluntad de quien produjo el documento, o por sugerencia del sistema de algoritmos de la red social, que, entre otras acciones, suele recordar eventos importantes y celebraciones, así como textos asociados a ellos.

Las palabras claves aplicadas en los primeros momentos de rastreo fueron: gramática, ortografía, lengua, idioma, diccionario, lingüística, lengua oficial, idioma oficial, oficialización, castellano, español, español de Chile. En la segunda tanda se añadió además lenguaje inclusivo, lenguaje feminista. En la última tanda se añadió además chilenismo y diccionario de chilenismos en la búsqueda.

Ya que el alcance de un grupo o página de Facebook es potencialmente global, para reconocer si corresponde o no al ámbito nacional chileno (es decir, al cierre político-espacial del objeto de estudio) se recurrió al reconocimiento de las localidades donde se encuentran sus administradores. Estos datos están disponibles para cada página o comunidad de Facebook en la sección de "Información”. Para el presente trabajo solo se seleccionaron grupos cuyos gestores estuviesen en su totalidad (o muy mayoritariamente) dentro de los límites de Chile, dejando al margen a aquellos grupos y comunidades que fuesen administrados desde otros territorios.

La etapa de rastreo con palabras clave tuvo como objetivo: 1) detectar grupos y páginas de Facebook enfocados en problemas de lengua en Chile (no solo de español, sino también de lenguas extranjeras e indígenas); 2) apreciar el impacto 
relativo de estos grupos, según la cantidad (y calidad) de participantes, de contenidos y comentarios; 3 ) seleccionar grupos susceptibles al análisis de lectura crítica, considerando su nivel de impacto.

La segunda etapa de análisis correspondió a la lectura crítica, e incluye el examen y discusión de determinadas ideologías lingüísticas encontradas en el corpus. Se presta particular atención a aquellas ya desglosadas por la teoría, por ejemplo, autenticidad y anonimato (Woolard, 2007) y orgullo y ganancia económica (Heller y Duchêne, 2012). Al comienzo de la indagación se supuso la relevancia de estas categorías de análisis en la configuración del español en Chile, lo que, como discutimos luego, no ocurriría por completo.

En la metodología utilizada aquí es clave la flexibilidad de acceso a los datos y de los modos de análisis de las dos etapas descritas. Como Blommaert (2014) propone, los métodos que permiten alcanzar la descripción de la complejidad requieren establecer nuevas nociones de contexto que contemplen posibilidades de sentido lo más amplias posible, para lo cual es preciso diseñar métodos flexibles de análisis de datos. En este sentido, es preciso entender que la búsqueda con palabras clave ha de constituir un punto de entrada, una forma de canalización los datos, pero no debe establecerse como un sistema que constriña el acceso a información relevante. Las listas de palabras clave y los ámbitos de búsqueda por ello no deben concebirse como fijos; es preciso pensarlos como abiertos a la interconexión en red propia del acceso de documentos en línea. Asimismo, los cierres espaciales y cronológicos, los ámbitos culturales, nacionales y étnicos aquí descritos son ilustrativos solo si se contemplan posibilidades de transformación y movilidad y con los diversos niveles de análisis que ponen en evidencia la complejidad del sistema. Como sugieren Blommaert y Rampton (2011) una indagación en torno a esta complejidad demanda un análisis de los cimientos políticos e históricos de las políticas de lenguas que han estado activas en un determinado entorno.

\section{Hallazgos}

La etapa de rastreo condujo a diversos descubrimientos de interés. En primer lugar, los grupos de Facebook que se han movilizado en el periodo estudiado sobre el español desde una institucionalidad están articulados de una manera transnacional y no se inscriben dentro de proyectos dirigidos al ámbito chileno.

Esto era hasta cierto punto esperable considerando que el español es una lengua con alcance transnacional; lo singular, no obstante, es la omisión por parte de la institucionalidad académica tradicional al momento de establecer espacios digitales en Chile. Era de esperarse encontrar comunidades o páginas en Facebook gestionadas por universidades públicas o privadas, y que ministerios u otras organizaciones gubernamentales o instituciones educativas gestionaran políticas de lengua, lo cual no ocurrió. Notablemente, la Academia Chilena de la Lengua no mantuvo espacios en la red social en el periodo estudiado. Recién a inicios de 2020, esta institución comenzó una cuenta de Twitter y una página de Facebook, que en junio del mismo año no alcanzaba a tener 100 seguidores. Las ocasiones en que se había mencionado esta institución en Facebook se dieron por iniciativa de ASALE o de la Real Academia Española, que sí han tenido a su cargo cuentas sumamente activas en la red social. Esto es consistente con el régimen de lengua predominante, según el cual la autoridad lingüística está relegada a una irradiación transnacional de orden panhispánico (Del Valle, 2007; Lauria, 2017). Los organismos a cargo de dicha autoridad han procurado establecer espacios digitales que apoyan y perpetúan dicha 
irradiación, los cuales consisten en comunidades y páginas de Facebook con una amplia base de seguidores a nivel global. La Real Academia de la Lengua (RAE) tenía en Facebook 330 mil “me gusta” en julio de 2019. Fundéu o Fundación Español Urgente, una organización de carácter privado dedicada a la promoción de la norma del idioma, con apoyo logístico y político de RAE, contaba por su parte con 100 mil para la misma fecha. El Instituto Cervantes, organización que promueve la enseñanza de la lengua española en el contexto internacional, dependiente del Estado español, tenía 67 mil "me gusta". En cambio, la Asociación de Academias de la Lengua Española (ASALE), que agrupa a todas las academias de la lengua española del mundo convocaba apenas 5.200 "me gusta”, en contraste con la visible popularidad de la RAE y Fundéu. Esta configuración refleja la fortaleza hegemónica de instituciones dedicadas a la producción de regímenes metadiscursivos, donde la gestión del español se encuentra fuertemente institucionalizada en una escala global, en un orden geopolítico donde España sigue a la cabeza y América Latina en una periferia. Según este mismo orden, el español estándar (y con ello, imaginado como correcto) se configura como situado fuera de los límites de Chile.

No obstante, una comparación de las cifras de adhesión a páginas de RAE, ASALE, Fundéu y el Instituto Cervantes (administradas desde España) con las de grupos de gestión del mapudungun en Facebook (administradas desde Chile) sugiere que las instituciones de gestión transnacional del español alcanzan un número relativamente moderado de seguidores, especialmente considerando su envergadura geopolítica y sus recursos económicos. El grupo Kimeltuwe ('lugar de enseñanza') corresponde a la organización de mayor influencia dentro de las políticas lingüísticas del mapudungun en años recientes, con 190 mil seguidores en Facebook en agosto de 2019 y 217 mil en junio de 2020. Emergió en el ámbito digital mediante la producción de imágenes educativas que abordan el vocabulario y la gramática del idioma mapuche, tocando además temáticas culturales y políticas. Las imágenes a menudo están en formato de meme, son llamativas, didácticas y resultan amables para el público general, por lo que rápidamente se difundirían por las redes sociales. Dado su éxito, Kimeltuwe al tiempo adquirió también un rol regulatorio, convirtiéndose en un actor clave en la planificación lingüística del mapudungun en el siglo XXI. Uno de sus principales gestores, Víctor Carilaf, en el periódico chileno The Clinic (Milos, 2019) afirmó: "Pasamos a ser un referente: si tienen dudas, nos preguntan a nosotros. Y si Kimeltuwe dice que se dice así, es así”. Hacia 2020 Kimeltuwe ya ha logrado establecer legitimidad lingüística y posicionarse como una autoridad activa en cuestiones de planificación de corpus.

Ahora bien, es importante tener presente que estos números no se corresponden necesariamente con un mayor o menor nivel de influencia. Indudablemente, el proyecto Kimeltuwe dispone de mucho menos poder institucional que Fundéu, aunque ostente el doble de seguidores en la red social. Comparar ambos grupos arroja luz sobre cómo Facebook resulta propicio para generar nuevos ámbitos desde donde se proyectan institucionalidades emergentes, cuyos discursos de reivindicación, transformación o reafirmación logran convocar a comunidades que hasta hace muy pocos años no eran susceptibles de ser articuladas. Es posible que organizaciones históricamente asentadas con un respaldo económico y político consolidado (como es el caso de Fundéu o el Instituto Cervantes) logren una relativamente menor convocatoria en Facebook no debido a su baja penetración social, sino a que ya ocupan espacios políticos establecidos. Esto las aparta de las comunidades digitales emergentes como Kimeltuwe, configuradas virtualmente desde cero, que gestionan proyectos político-lingüísticos más localizados, pero con un potencial de expansión mucho mayor. 
En este sentido, tal como han emergido grupos de gestión de lengua mapuche, cabe preguntarse si se detectaron espacios de gestión del español de Chile según sus peculiaridades nacionales y qué pasa además con reivindicaciones de gestión de lengua propias que apuntan a una transformación entre género, poder, y sexualidad.

Es indudable la entrada de grupos que buscan cuestionar y replantear los presupuestos de sexo y género en la lengua española en pos de proyectos de justicia social han alcanzado amplia resonancia a partir de 2010. La aparición en países de lengua española de numerosas guías para el uso feminista del lenguaje, y del lenguaje inclusivo (o no-discriminatorio por identidad de género o sexual) es demostrativo de esta tendencia (Lagneaux, 2017). Significativamente, en la fase de rastreo de la presente investigación se detectaron únicamente espacios digitales dirigidos desde fuera de Chile y pensados en una escala transnacional de la lengua española. Por ejemplo, están las comunidades de Facebook Campaña por la incorporación del lenguaje inclusivo (con unos 16 mil "me gusta" en octubre de 2019) y la agrupación Lenguaje inclusivo (con 2.500), que fueron creadas en Argentina y que, a pesar de que poseen una clara resonancia en Chile en algunos circuitos, no poseen equivalentes locales. Esta ausencia es informativa de que, en paralelo con otras cuestiones consideradas globales en la gestión del español, la discusión y administración del espacio político donde se entrecruzan lenguaje, identidad, género y sexualidad suele ocurrir en una configuración escalar donde Chile está en la periferia.

Por otro lado, la gestión y redefinición política del español chileno con ánimo nacionalista no se expresa por medio de páginas y grupos de Facebook: en el rastreo efectuado aquí no se detectaron grupos dedicados específicamente a la exacerbación del vínculo entre lengua e identidad nacional. Ello contrasta con lo que sucede con grupos de revitalización de la lengua mapuche (como el mencionado Kimeltuwe) donde a ratos se observa una voluntad intencionada de crear un vínculo simbólico entre lengua, cultura e identidad, dirigido a enfatizar o celebrar un carácter nacional de la comunidad mapuche.

Sin embargo, sí se hallaron algunas escasas agrupaciones enfocadas a la celebración de los chilenismos o del habla nacional de Chile, a menudo en tono jocoso o festivo. Efectivamente, en las búsquedas de agosto 2018 se documentan solo dos comunidades y páginas: No hablo español, hablo chileno (con 980 seguidores en junio 2020) y Chilenismos (con 3.600, en la misma fecha). Aunque se infiere que hubo en ellas en algún momento la intención de incorporar temas de lengua e identidad, en verdad tienen por propósito producir contenidos humorísticos sin tocar problemáticas identitarias ni de lengua strictu senso y no han adquirido notoriedad. Esto probablemente indica que ha habido muy escasos espacios dedicados específicamente para la articulación de discursos reivindicativos sobre la lengua castellana para Chile dentro de Facebook.

Existe, sin embargo, una notable excepción. Otra comunidad, llamada Hablai chileno?, da muestra de diversas innovaciones dirigidas a reimaginar e incluso subvertir el tropo de que en "En Chile se habla mal". Según su sección de descripción (revisada en agosto de 2019), el grupo se dedica al "análisis gramatical del habla chilena" y a producir "recursos lingüísticos para aprender a hablar chileno". Una lectura crítica revela que Hablai chileno? está integrada por una congregación de personas con conocimientos e inquietudes sobre temas de lengua, dedicadas a refutar ideas negativas en torno al español hablado en Chile. En rigor, no se ocupa de analizar la gramática y promover el uso del idioma chileno, sino en cuestionar los presupuestos que minimizan su valor sociocultural. 
Hay un ejemplo de ello (fechado el 18 de noviembre de 2018) cuando un participante del grupo publicó una imagen donde se muestra un receptáculo lleno de pebre (aderezo crudo compuesto de tomate, cebolla, cilantro y ají picados) junto a un pimiento rojo. En Chile el pebre se imagina como un producto típico, representativo de lo nacional, no obstante su afinidad a preparados como el chimichurri rioplatense, la llajwa de Bolivia o el pico de gallo de México. Acompaña a la imagen un texto que enuncia: "¿Cachabay que la palabra piper en latín se convirtió en pebre en chileno y pepper en inglés?”, al cual se añaden el comentario “puta que hablamos mal el latín los chilenos", además de un emoji pícaro, con la lengua afuera (*)

Posteriormente, el autor del documento incorpora en los comentarios un breve cuadro derivativo de voces latinas en español, y también en inglés, italiano y francés (piper, pepper, pepe, poivre) al que adjunta una referencia bibliográfica. Este documento es decidor de una representación muy novedosa en torno a la lengua chilena: la presenta en una línea de continuidad histórica con el latín, al tiempo que deja al margen los elementos hispánico e indígena como pertinentes para su configuración. Se establece así una narrativa que recurre a un argumento de base lingüístico-comparativa para desmontar la premisa de qué supone exactamente hablar mal. Sugiere que el idioma de Chile incluso en sus aspectos más banales e impensados (tales como el nombre de un aderezo) participa de un contínuum histórico-cultural con lenguas internacionales prestigiosas y que todas ellas están sujetas a mecanismos afines de transformación temporal. De este modo, se insinúa que el español de Chile y el inglés o el francés no difieren en su textura más íntima y que las atribuciones que se dan a dichas lenguas obedecen, seguramente, a factores extralingüísticos. Finalmente, mediante la inserción del comentario de que "puta hablamos mal el latín los chilenos..." se ironiza con la ideología de la incorrección de la lengua chilena, de momento que cuestiona los fundamentos que lo constituyen. Cuando se piensa una lengua ya no como una entidad fija, estable y de límites definidos, sino como una concurrencia de hechos lingüísticos dispares y en constante mutación, nociones arraigadas de norma y corrección necesariamente quedan en entredicho. Nótese además que añade la interjección "puta" -predominante en el uso coloquial en Chile y afín a otras voces de tabú sexual expresivas (coño, mierda, fuck)- de modo que el contrapunto entre el cuestionamiento de nociones históricas de corrección lingüística y el uso interjectivo de un vocablo vulgar finalmente magnifican los ecos de la ironía.

Ahora bien, Hablai chileno? tiene un alcance relativamente limitado. En agosto de 2019 los "me gusta" superaban apenas los 3.500. La cantidad de posteos que incluye es bastante pequeña, sus publicaciones son infrecuentes, y las secciones de comentarios son sucintas. Esto quiere decir que la agrupación carece de resonancia en Facebook y en el ámbito público. Tampoco se documentan entre sus contenidos los supuestos "recursos para aprender a hablar chileno" anunciados en su descripción. Solo se registran instancias donde se promueven los chilenismos con entusiasmo, se defiende el uso del voseo chileno, y se proponen ciertas normativas ortográficas, pero ninguno de estos contenidos evidencia un afán definidamente didáctico.

Esto es coherente con el hallazgo principal resultante del proceso de rastreo en el corpus digital: que más allá de la agrupación Hablai chileno? en el presente análisis no se encontraron grupos relevantes dedicados a temas de lengua española en Chile o que incorporasen al español nacional como elemento central de sus intereses. Este vacío es señal del alto grado de despolitización de la lengua española en la consciencia pública, en particular dado el contraste con la vitalidad política del mapudungun. 
Es así que el ideologema de que en Chile se habla mal, al menos según se evidencia en Facebook, no moviliza con urgencia a que la población ajuste su idioma a la norma estándar y tampoco la empuja a que busque autonomizar ni formalizar su diferencia lingüística. $i$ Implica esto que la población chilena no vierte sus problemáticas de lengua e identidad a la red social? ¿Qué ocurre con las representaciones de anonimato, autenticidad y orgullo descritas por la teoría en otros ámbitos? ¿En qué instancias de Facebook sería posible encontrar este tipo de ideologías de lengua?

Fue preciso entonces replantear el modo de rastreo y selección de corpus de Facebook para detectar espacios donde se pusieran en relieve ideologías de lengua, y recurrir intuitivamente a intersticios de la red social donde dichas ideologías se codificasen de modo ilustrativo y, finalmente, conducente a una etapa de lectura crítica más informativa. Con el fin de resolver esta cuestión se hizo un sondeo a páginas y comunidades de Facebook intervenidas por tropos de identidad nacional donde se desplegasen problemas de lengua de manera densa e informativa. Era fundamental que contaran con muchos seguidores (índice de un alto impacto social), lo que propiciaría intercambios nutridos y dilatados en torno a diversos temas, incluido lo lingüístico. Luego de evaluar espacios digitales dedicados a folclor, tradiciones chilenas, gastronomía, partidos políticos, organizaciones municipales y regionales, y otras, hemos optado por seguir la pista a sitios humorísticos donde se ironiza sobre clichés identitarios. Estos corresponden a páginas/comunidades de humor que permiten acceder a discursos en torno a lengua, identidad y clase social de un modo que se puede vincular rápidamente con lo político.

Las comunidades de tipo "Es de..." se caracterizan por la producción y difusión de memes que constan de un único texto breve, por lo general una consigna en clave de humor articulada con una premisa identitaria, por ejemplo: "es de roto / depilarse el pecho"; "es de cuica / que tu mamá esté bronceada todo el año"; "es de mapushe (sic)/ ser informante para una tesis". Estas articulaciones permiten que los ideologemas expresados circulen en dominios como Facebook o Twitter con fluidez mediante hashtags (\#esdecuica; \# esderoto), volviéndolos fácilmente rastreables en el medio digital.

Se eligieron los dos espacios de este tipo de mayor dinamismo y repercusión: Es de roto (con 522 mil seguidores en agosto de 2019) y Es de cuica (340 mil en la misma fecha). Al tiempo que proveen abundantes discursos explícitos acerca de lo lingüístico, también han trascendido más allá del ámbito digital; sus gestores tienen a su haber publicaciones de libros y apariciones en medios hegemónicos, particularmente en prensa y televisión.

Además, el componente de clase social constituye el núcleo más relevante para un análisis crítico de los problemas de lengua, nación y sociedad en Chile, un país donde las distinciones de clase son sumamente acusadas y la pertenencia a un cierto estrato determina casi por completo el modo y las experiencias de vida de cada persona. En este orden, la lengua es clave para la constitución y la perpetuación de límites de clase, constituyendo un territorio de permanente disputa y negociación (Woolard, 2007; Gal y Woolard, 2001; Kroskrity, 2000). Convenientemente, el contraste entre las figuras discursivas del roto y la cuica da pie a un análisis altamente provechoso, toda vez que aborda dos representaciones prototípicas diversas (y hasta cierto punto complementarias) de autenticidad y legitimidad de lo chileno, posicionadas en una dialéctica compleja donde la clase social es el elemento central, pero no el único, de producción de sentido.

En el orden simbólico de clase social chileno, la figura del roto remite al prototipo del mestizo de la clase trabajadora urbana, históricamente vilipendiado por su percibida falta de modales y de educación (Gutiérrez, 2010; Plath, 1957). Sin 
embargo, el grupo de Facebook Es de roto no participa en una estigmatización de las clases populares; por el contrario, se aboca a celebrar sus singularidades idiosincráticas, entendiéndolas como equívocos culturales propios del carácter singular de los chilenos.

En contraste, la cuica, es el prototipo de la hija y madre de familia adinerada, típicamente blanca y con apellidos que la localizan de modo inequívoco en su origen social. La cuica se identifica como guardiana de los rasgos que definen tanto su clase como su género, y aunque se suele concebir como conservadora, está también fuertemente influenciada por la cultura global y el consumo.

Una lectura crítica de los documentos que circulan en Es de cuica sugiere que en este espacio se subraya en tono liviano e irónico las peculiaridades que constituyen índices de clase, entre las que destacan las de índole lingüística. Así lo sugiere un meme publicado el 31 de mayo de 2016 que dice “\#Esdecuica hablar spanglish, if you know what I mean”. En él se saca a relucir el conocimiento del spanglish (entendido una hibridación lingüística que combina elementos del español y del inglés) como índice de autenticidad de pertenencia a una clase acomodada. El gran número de comentarios (más de 800 en julio de 2019), "me gusta" (más de 5 mil) y reposteos (unos 1.100) resulta demostrativo de la actitud general que la comunidad y sus seguidores tienen sobre este asunto: lo sienten como algo revelador (y un tanto risible) de una praxis cultural.

En este sentido, es destacable el hecho de cómo se articula una identidad de clase social distintiva a partir del concepto "spanglish", sobre todo considerando que la norma panhispánica más purista deplora dicha hibridación. Ello se demuestra en el artículo del diario chileno El Mercurio "La pegajosa moda de hablar y vender con anglicismos" (5 de agosto de 2012) donde diversas autoridades idiomáticas (lingüistas y académicos de la lengua de Chile y de España, entre ellos) expresan su preocupación por el "excesivo" uso del inglés, especialmente cuando hay una "mezcla" con el español. Jactarse de la hibridación implicada en el concepto spanglish entonces debería encender todas las alarmas entre quienes custodian las costumbres de la élite. ¿Por qué la clase dirigente de Chile aquí parece hacer oídos sordos a la reglamentación lingüística?

En el contexto chileno la habilidad de hablar lenguas internacionales de origen europeo $-\mathrm{y}$ en particular el inglés- se reconoce como un rasgo atribuible a la clase alta del país. Esto ocurre no solo porque parte importante de la élite ha podido viajar y formarse en Europa, Norteamérica y Asia, sino también porque por generaciones muchos de ellos han asistido a escuelas y colegios bilingües (Menard-Warwick, 2012; Matear, 2008). En consecuencia, la cuica al declarar que "habla spanglish" no promueve la hibridación de formas lingüísticas, sino que anuncia públicamente que el inglés es parte de su repertorio cotidiano y que puede alternar entre dos idiomas con fluidez de un modo que personas de otras clases sociales no serían capaces. Este sentido de spanglish, entonces, se contrapone al valor descrito en los orígenes del término, como una forma de lengua marginal, propia de grupos subalternos en Estados Unidos (Otheguy y Stern, 2010). Se observa entonces una ideología de orgullo de clase donde no se celebra la mezcla de las lenguas, sino la capacidad de distinguirse mediante un código en general vedado a la mayoría de la población.

Otro caso revelador corresponde al 10 de mayo de 2017 donde en Es de cuica se anunció que está "prohibido decirle 'mami' a la mamá". El documento (con 1.900 "me gusta”) fue ampliamente compartido y hacia julio de 2019 acumulaba 
364 comentarios. En ellos se observa que una mayoría de participantes considera el término mami como vulgar o risible y que, en varias ocasiones, se pide derechamente que no se utilice. Según se observa en los comentarios, se sugiere que quienes emplean el término mami se hallan al extremo inferior del espectro social y que la clase alta prefiere mamá, madre, mom e incluso expresiones como mi amá. Predomina de este modo una percepción del habla de las clases dirigentes como la forma de más alto valor en el mercado lingüístico y, dadas sus connotaciones positivas, rápidamente es representada como "correcta" o "agradable". A ella queda opuesta el habla "flaite" de las clases populares, imaginada como cualitativamente inferior (Rojas, 2012b).

En muchos comentarios, no obstante, se defiende la validez de mami, en especial debido a su aspecto afectivo, vinculado a una singularidad emocional en la relación maternofilial. Una participante sostiene: “a m[í] los 2 enanos me dicen mami [...] suena tierno en los niños chiquititos [...] En lo[s] grandes no me gusta, [...] [lo] encuentro flaite". Y añade: "los regg[a] etoneros lo arruinaron". En esta sentencia se presentan diversas matrices de sentido que analizadas en conjunto llevan a dimensiones significativamente políticas. Primero, mami sería un uso infantilizado e impregnado de afecto, que hace eco en un universo fundamentalmente femenino. Luego está la marcación de inferioridad por clase social, tal vez novedosa para la comentarista. Y finalmente se observa una posible razón que localiza el origen de dicha inferioridad: el uso amplio de la palabra entre "reggaetoneros".

Atribuir la inadecuación o incorrección del término mami a la influencia del lenguaje sexualizado y foráneo del reggaetón tiene sentido en tanto este género musical se asocia a las clases populares latinoamericanas más allá de las fronteras de Chile. Rojas (2012a) observa que en Santiago el español puertorriqueño, en particular, está valorado de manera marcadamente negativa. El reggaetón (género nacido en Puerto Rico y difundido desde allí) si bien es popular entre los jóvenes de todos los estratos sociales, suele imaginarse como algo propio de las clases bajas. Es probable, por lo tanto, que la amplia desaprobación de la variante dialectal puertorriqueña en Chile obedezca no solo a la posición marginal del español caribeño dentro del orden panhispánico de corrección lingüística, sino que también a una iconización estrecha entre un gusto predominante de las masas populares y las estrategias de constitución identitaria resueltas por la élite, determinadas en buena medida por contraste y exclusión.

Asimismo, el contrapunto entre una percepción de la forma mami como infantil y afectuosa y otra como sexualizada y fuertemente localizada en sujetos de las clases bajas resulta también revelador de problemáticas de género, nación e identidad. Ello queda en evidencia cuando en los comentarios una mujer declara: "mami en tono caribeño, lo amo". Este comentario posiciona el término en el plano de lo erótico, dando pie a una semiosis compleja donde intervienen, de manera peculiar, lengua, clase social, género, sexualidad y geopolítica. Ello va de la mano con ciertas especificidades del reggaetón como género musical, cargado de representaciones de los cuerpos (y del idioma) de hombres y mujeres del Caribe, casi siempre visiones eróticas de carácter racializado, juvenil y heterosexual. En el contexto de Chile, estas visiones proyectan el imaginario de una geografía cultural ajena, pero legible gracias a la lengua en común, idealizada como territorio donde prevalecen la sensualidad y el placer. De este modo, la mujer residente en dichos imaginarios (la mami) se contrapone al orden racial, cultural y moral establecido por las élites nacionales al momento de pensarse a sí mismas, lo que deriva en su censura. A ello se suma que el rechazo de la utilización de mami coincide con un esquema histórico de marginación selectiva de elementos latinoamericanos en el gusto establecido por las clases dominantes, algo demostrado 
ya en otras épocas, dada su denostación por la cumbia, la huaracha, las rancheras, y otras expresiones culturales muy extendidas entre la población general pero inadmisibles para la clase dirigente, las cuales tienen en común una producción en lengua española y un origen geopolítico situado lejos del ideal europeo.

Entonces aquí se reproduce un esquema donde ciertas variedades del español se imaginan como "superiores" e "inferiores". Y, notablemente, el ideologema de que "en Chile se habla mal" se actualiza a partir de una supuesta influencia negativa a través de la cultura popular, que supondría que en Chile se habla "aún peor" debido a la influencia del español del Caribe.

A pesar de esta visión, existen señales de que el castellano chileno es a veces celebrado bajo una luz positiva, especialmente el de las clases populares, por ejemplo, en la página de Facebook Es de roto.

A diferencia de Hablai chileno?, la comunidad Es de roto no se enfoca en la discusión la variedad lingüística del país, sino que simplemente señala su diferencia y la reposiciona como un objeto de valor cultural. Es probable que su éxito obedezca a que, en un tono despreocupado y festivo, habla de costumbres susceptibles de señalarse como propias de las clases bajas, pero que en realidad pueden ser más o menos comunes en todos los estratos de la población. Esto permite a los miembros de la comunidad hacer mofa de las inflexibilidades y contradicciones de la norma social, pero sin desentenderse de que en la sociedad chilena las divisiones de clase persisten con firmeza ni de que las inequidades constituyen una problemática central.

Un ejemplo de ello está en el meme publicado por los administradores de la comunidad el 16 de diciembre de 2016 que declara “\#Esderoto decir 'soy tu fanS', añadiendo un vistoso (e hiperbólico) Fansssssssssssszzzz. En julio de 2019 el meme acumulaba 5.300 me gusta, 680 comentarios y unos 800 reposteos. El texto ironiza sobre el uso de sustantivo singular fans ('admirador/a') en lugar de la forma canónica fan de voz de personas pertenecientes a los estratos sociales medios y bajos. La forma cuestionada ha aparecido probablemente por ultracorrección, es decir, a causa de la tendencia de los hablantes del español chileno a elidir el fonema -/s/ en posición final de sílaba, lo que conduce a inferir una sibilante que luego se agrega con fines correctivos. El fenómeno parece reiterarse en casos de otros vocablos de origen inglés entre quienes, es de presumir, no saben hablar dicha lengua; por ejemplo, entre los comentarios de la imagen se citan babysister (por babysitter) y dar un tips (en lugar de tip). Se atestigua así que el sustantivo singular fans en el contexto de Chile contemporáneo se ha convertido en un índice de clase social.

La importancia del caso de "soy tu fans" no obstante yace en cómo revela una dimensión en que los atributos del roto adquieren un nuevo valor identitario. Entre los comentarios más relevantes está el de una mujer que sostiene haberle escrito por Twitter "soy tu fans" al actor de habla inglesa Robert Carlyle. Aun cuando ella cuenta que esto igualmente le causó un poco de vergüenza, la infracción cometida pierde relevancia frente al contacto real entre una celebridad mundial y una "fans" de un país remoto. En su comentario, la admiradora deja entrever que la comunicación aconteció no solo a pesar de sus percibidas inhabilidades lingüísticas, sino que también gracias a ellas. De este modo, cuando la frase "soy tu fans" se pone bajo escrutinio, se celebra igualmente con entusiasmo, reposicionando a la figura del roto dentro del esquema social, vinculándolo, al menos ocasionalmente, a un discurso de orgullo cultural. 


\section{Conclusiones}

A partir de la lectura crítica de los espacios digitales estudiados, en el presente artículo se han analizado microdinámicas de la comunicación social en ámbitos digitales, las cuales informan acerca de esquemas macrosociales de la lengua española en/de Chile. Se observó, entre otras cosas, que cuando la cuica enfatiza que "habla spanglish", se pone en relieve que las voces de origen inglés son consideradas prestigiosas en su entorno social e incluso las incorpora como elementos clave de su legitimidad identitaria. La ideología de autenticidad (Woolard, 2007) se encuentra aquí compenetrada con la necesidad de defender los límites de clase social. En cambio, el roto, al momento que dice "soy tu fans", queda puesto en evidencia en su supuesta inferioridad cultural, pues demuestra un desconocimiento de las reglas de uso de las voces de origen inglés en el ámbito chileno.

El contraste entre ambas operaciones sobre la lengua es decidor de una desigual distribución de recursos simbólicos, cuya inequidad fundamental no está necesariamente establecida por una autoridad formal ni por dictámenes institucionales. Como sugiere Bourdieu (1984), la reproducción y el control del capital lingüístico ocurren de acuerdo con procesos que crean distinción por parte de las clases dirigentes en el contexto de la sociedad. Estos procesos convierten hábitos sociales adquiridos en impulsos percibidos como propios del carácter individual, como por ejemplo, el gusto referente las preferencias musicales o el modo de vestir. Dichos impulsos se naturalizan en el estilo de vida en un habitus, al tiempo que se convienrten en índices codificadores de clase social, así como también en modos de dominación. En esta línea, el rechazo de la clase alta a la palabra mami (y así también al reggaetón) constituye una táctica de distinción que la aparta de los usos culturales propios de las clases populares, subrayando una diferencia que va más allá de lo cultural y se instala en el ámbito de las relaciones de poder.

Se ha observado también aquí cómo la táctica de distinción se acopla a la preeminencia de formas sentidas como "correctas" o "superiores", en adhesión aparente a una ideología de la lengua estándar (Milroy, 2001). Algo peculiar del caso visto, no obstante, es que la clase dirigente chilena no parece identificar necesariamente el estándar transnacional del español con su lengua propia y activamente desatiende demandas puristas por parte de la autoridad académica, en particular con respecto al uso de vocablos de origen inglés. Posiblemente, la adhesión estrecha a la norma del español transnacional, anónimo y transparente, regulado por las academias de la lengua, resulta menos útil para la marcación de clase social en Chile, al contrario de lo que ocurre, por ejemplo, en Perú (De los Heros, 2012) o Colombia (Chaves-O'Flynn, 2017). Significativamente, aunque estos son países cuyas variedades de lengua principales son consideradas "superiores", estas no son necesariamente sentidas como modelo lingüístico por la población chilena (Rojas, 2012c).

El análisis presentado también informa de la aparición de un tropo de orgullo crítico al eurocentrismo ideológico del proyecto nacional chileno, que revalora las singularidades lingüísticas y culturales de las clases populares de origen mestizo y de la comunidad mapuche. En este sentido, el orgullo se sitúa menos en discursos funcionales al sentido tradicional de nación (impulsado históricamente por las élites chilenas) y más en el despliegue de reivindicaciones emergentes de grupos históricamente marginados. En concordancia con ello, la celebración de la identidad lingüística del roto en Facebook y el éxito del proyecto de revitalización del mapudungun de Kimeltuwe brindan evidencia de una constitución de nuevos 
sujetos políticos en el contexto contemporáneo. Esto es afín con procesos donde también se han articulado ideologías de orgullo en otros países, por ejemplo, en comunidades francófonas de Canadá (Heller y Duchêne, 2012).

Por su parte, el español anónimo, transparente y naturalizado en el sistema educativo, sostenido por las asimetrías simbólicas del modelo panhispánico de autoridad lingüística es raramente cuestionado en su estatus hegemónico. La excepción corresponde al grupo Hablai chileno? que, de modo bastante marginal, ha buscado subvertir las presuposiciones de aquella asimetría y la cuestiona valiéndose de la misma sustancia que la constituye: la producción de discursos de lengua con legitimidad social. Notablemente, no se detectaron más iniciativas conducentes al replanteamiento del modelo de autoridad en torno a la lengua nacional, ni siquiera en cuanto a cuestiones fuertemente ligadas a movilizaciones político-lingüísticas contemporáneas, como el problema del sexismo en el lenguaje y las estrategias para combatirlo.

En este sentido, la etapa de rastreo también arrojó información muy relevante. Se evidenció la relativamente escasa movilización en torno a políticas de lengua española en Chile, lo que demuestra una posible despolitización y una minimización de los problemas sociolingüísticos como relevantes en el seno de la nación. Ello ocurre no solo por parte de la población que participa en redes sociales, sino también por parte de la institucionalidad académica, universidades y organizaciones gubernamentales. No obstante, probablemente este vacío también esté influenciado por el carácter relativamente novedoso de las redes sociales como Facebook. En la medida que se asiente el uso de estas redes como medios primordiales de comunicación social puede que la institucionalidad tradicional de la lengua española en Chile también adquiera un peso y una presencia cada vez mayor, emulando lo que ha sucedido con grupos emergentes de gestión lingüística como Kimeltuwe. Dado el carácter saturado de lo político en las redes digitales en la década que comienza, es esperable que pronto otros análisis en torno a estas problemáticas indiquen una renovada politización de la lengua española en el contexto chileno.

\section{Referencias bibliográficas}

Arnoux, E.N. y J. del Valle. (2010). Las representaciones ideológicas del lenguaje: discurso glotopolítico y panhispanismo. Spanish in Context 7: 1, 1-24.

Blommaert, J. (2014). From mobility to complexity in sociolinguistic theory and method. Working Papers in Urban Languages and Literacies, 35: 1-17.

Blommaert, J. y B. Rampton. (2011). Language and superdiversity. Diversities, Vol. 13, No. 2, 2011. Disponible en: www. unesco.org/shs/diversities/vol13/issue2/art1. Consultado: 10 de marzo de 2016.

Blommaert, J., Kelly-Holmes, H., Lane, P., Leppänen, S., Moriarty, M., Pietikäinen, S., y Piirainen-Marsh, A. (2009). Media, multilingualism and language policing: An introduction. Language Policy, 8(3), 203-207.

Bourdieu, P. (1984). Distinction: A Critique of the social judgement of Taste. Cambridge, Mass.: Harvard University Press.

Bourdieu, P. (1991). Language and symbolic power. Cambridge, Mass.: Harvard University Press.

Cameron, D. (2012). Verbal hygiene. Londres: Routledge. 
Chaves-O’Flynn, C. (2017). Lengua y violencias en Colombia: Discursos sobre patrimonio lingüístico (1991-2010). [Tesis de doctorado, City University of New York] https://academicworks.cuny.edu/gc_etds/1916/

De los Heros, S. (2012): Utopía y realidad: nociones sobre el estándar lingüístico en la esfera intelectual y educativa peruana. Frankfurt/Madrid: Vervuert-Iberoamericana.

Del Valle, J. (2007). La lengua, patria común: la "hispanofonía” y el nacionalismo panhispánico. En: J. del Valle, La lengua, ¿patria común? Ideas e ideologías del español. Frankfurt/Madrid: Vervuert-Iberoamericana, 31-56.

Del Valle, J. (2014). “Lo político del lenguaje y los límites de la política lingüística panhispánica”, Boletín de Filología XLIV (2), 87-112.

Del Valle, J. (2017). La perspectiva glotopolítica y la normatividad. AGlo. Anuario de Glotopolítica, (1), 17-39.

Del Valle, J. y V. Meirinho. V. (2016). Ideologías lingüísticas. https://academicworks.cuny.edu/cgi/viewcontent. cgi?article=1273\&context=gc_pubs Consultado: 11 de octubre 2016.

Deumert, A. (2014). Sociolinguistics and mobile communication. Edimburgo: Edinburgh University Press, 100-121.

Gal, S. y K. Woolard. (2001a). Languages and publics: The making of authority. Manchester: St. Jerome, 1-12.

Gal, S. y K. Woolard. (2001b). Constructing Languages and Publics. Authority and Representation. En: S. Gal y K. Woolard (eds.) Languages and publics: the making of authority, Manchester: St. Jerome, 1-12.

García, O., y Otheguy, R. (2014). Spanish and Hispanic bilingualism. En: Routledge handbook of Hispanic applied linguistics, 655-674.

Gundermann, H. (2014). Orgullo cultural y ambivalencia: actitudes ante la lengua originaria en la sociedad mapuche contemporánea. RLA. Revista de lingüística teórica y aplicada, 52(1), 105-132.

Gutiérrez, H. (2010). Exaltación del mestizo: La invención del Roto Chileno. Universum (Talca), 25(1), 122-139.

Heller, M. y A. Duchêne. (2012). Pride and profit: changing discourses of language, capital and nation-state. En: M. Heller y A. Duchêne (eds.) Language in late capitalism: pride and profit. Londres/Nueva York: Routledge, 1-21.

Kroskrity, P. (2000). Regimenting Languages: Language Ideological Perspectives. En: P. Kroskrity (ed.) Regimes of Language: Ideologies, Polities, and Identities, Santa Fe, NM: School of American Research Press, 1-34.

Lagneaux, M. A. (2017). En lenguaje inclusivo y la escritura académica en la universidad. Periodismo y Comunicación, Vol. 3, N.o 1 .

Lauria, D. (2017). Avances en el estudio de los instrumentos lingüísticos actuales de la lengua española: los dispositivos normativos híbridos y express. Circula 6, 90-113.

Matear, A. (2008). English language learning and education policy in Chile: can English really open doors for all? Asia Pacific Journal of Education, 28(2), 131-147.

Menard-Warwick, J. (2013). English language teachers on the discursive faultlines: identities, ideologies and pedagogies, the case of Chile. Bristol: Multilingual Matters. 
Milos, D. (2019, 19 demarzo). Nuestrolema es mapudungun para todosytodas. The Clinic.https://www.theclinic.cl/2019/03/15/ nuestro-lema-es-mapuzugun-para-todos-y-todas/?fb_comment_id=2627427810632879_2629415713767422

Milroy, J. (2001). Language ideologies and the consequences of standardization. Journal of sociolinguistics, 5(4), 530-555. Otheguy, R., y Stern, N. (2011). On so-called Spanglish. International Journal of Bilingualism, 15(1), 85-100.

Phyak, P. (2015). (En) Countering language ideologies: language policing in the ideospace of Facebook. Language policy, 14(4), 377-395.

Plath, O. (1957). Epopeya del "roto" chileno". Autorretrato de Chile, Santiago, Chile: Zig-Zag,133-147.

Ricento T. (2015). Language Policy and Political Economy: English in a Global Context. Nueva York: Oxford University Press.

Rojas, D. (2012a). Corrección idiomática atribuida al español de los países hispanohablantes por sujetos de Santiago de Chile. RLA. Revista de lingüística teórica y aplicada, 50(2), 39-62.

Rojas, D. (2012b). Percepción y valoración de variedades geográficas del español de Chile entre hispanohablantes santiaguinos. Boletín de filología, 47(1), 227-232.

Rojas, D. (2012c). Actitudes lingüísticas de hispanohablantes de Santiago de Chile: creencias sobre la corrección idiomática. Onomázein: Revista de lingüística, filología y traducción de la Pontificia Universidad Católica de Chile, 26, 69-93.

Rojas, D. (2015). ¿Por qué los chilenos hablamos como hablamos? Santiago, Chile: Uqbar Editores.

Sliashynskaya, H. (2017). Multilingualism in Chile: representations of languages in Chilean news media discourse. [Conferencia, Birmingham University] https://www.birmingham.ac.uk/Documents/college-artslaw/corpus/conferencearchives/2017/general/paper349.pdf

TheEconomist. (2019,20dejulio)YoungstersareavoidingFacebookbutnot thefirm's otherplatforms. TheEconomist.https:// www.economist.com/graphic-detail/2019/07/20/youngsters-are-avoiding-facebook-but-not-the-firms-other-platforms Woolard, K. (2007). La autoridad lingüística del español y las ideologías de la autenticidad y el anonimato. En J. del Valle, La lengua, ¿patria común? Ideas e ideologías del español. Frankfurt/Madrid: Vervuert-Iberoamericana, 129-142.

Woolard, K. (2016). Singular and Plural: Ideologies of Linguistic Authority in 21st Century Catalonia. Oxford University Press. 
